\title{
PREVENTION OF INPATIENT SUICIDES: AN ATTEMPT TO PORTRAY AN APPROACH
}

\author{
Tony Thomas \\ Junior Consultant, Dept. of Psychiatry, General Hospital, Pala. \\ Correspondence: Junior Consultant, Dept. of Psychiatry, General Hospital, Pala. E-mail: tonythomaspallivathukal@gmail.com
}

\begin{abstract}
Inpatient Suicide (IPS) is the second most common sentinel event reported to the Joint Commission. Psychiatric inpatient suicide rates in the USA, China, New Zealand, Australia, and the UK range from $0.1 \%$ to $0.4 \%$ for all psychiatric admissions. Population-based mortality studies in psychiatric care show a 16 -fold risk for suicide among psychiatric inpatients and a 2-3-fold greater risk for outpatients compared to the risk for outpatients treated in primary care. The risk factors for suicides in inpatient setting and general population differ. Moreover, the identified risk factors for IPS have relatively low degree of association. Nevertheless, psychiatric inpatients are at a higher risk for suicide. This article discusses the spectrum Model of interventions for mental health protection proposed by Mrazek \& Haggarty, B-SAFE strategy, and SAFE$\mathrm{T}$ strategy. The above models portray a stepwise approach for inpatients who are "at risk" for suicide. Prevention strategies are to be specifically tailored for each individual, after carefully assessing the risk of suicide. Early diagnosis and proper treatment of psychiatric illness and modification of hospital environmental factors are the cornerstones in preventing inpatient suicides. The role of nursing and paramedical staff is also discussed.
\end{abstract}

Keywords: inpatient suicides, prevention strategies, hospital-environment factors

\section{INTRODUCTION}

Suicide among the general population: Worldwide, suicide is among the top three causes of death among young adults. According to the WHO, every year, almost one million people die from suicide and 20 times more people attempt suicide; a global mortality rate of 16 per 100,000 or one death every 40 seconds and one attempt every three seconds, on average. Globally, the burden of suicide in 1998 was estimated to represent $1.8 \%$ of the total global burden of disease. This figure is projected to be $2.4 \%$ by 2020 , especially in countries with socialist economies. ${ }^{1}$

Suicides in the inpatient setting: Inpatient suicide (IPS) is defined as "the suicide of a patient during inpatient treatment, both inside and outside the hospital setting.E.g., during a leave, outings, or trial discharge". ${ }^{2}$ IPS often indicate great patient distress and have devastating effects on survivors as well as on the staff morale. ${ }^{3}$ Failure to protect the admitted patients from harming themselves is one of the most common reasons for lawsuits in psychiatry. ${ }^{4}$ Hence, IPS prevention strategies are gaining importance and attention.

Incidence of IPS: IPS is the second most common sentinel event reported to the Joint Commission. Studies and statistics related to IPS are limited, as many cases are not appropriately reported, thereby masking the exact figures. Deliberate improperinadequate reporting and hiding of cases are mostly assumed to be for fear of lawsuits. ${ }^{3}$

Please cite this article as: Thomas T. Prevention of inpatient suicides: an attempt to portray an approach. Kerala Journal of Psychiatry 2017; 30(2):93-102. DOI: $10.30834 / K J P .30 .2 .2018 .47$ 
The prevalence of IPS is $0.1 \%$ to $0.4 \%$ for all psychiatric admissions. ${ }^{5,6,84}$ The rate of suicides in psychiatric inpatients is 13.7 per 10,000 admissions. ${ }^{7}$ Population-based mortality studies in psychiatric care show a 16-fold risk for suicide among psychiatric inpatients and a 2-3 fold greater risk for outpatients compared to the risk for outpatients treated in primary care. ${ }^{8}$ In a medical inpatient setting (patients admitted to the medical ward), the rate of suicides is less when compared to the psychiatric inpatient setting. Even though there is a wide array of studies, no accurate and concordant statistics on IPS is available. The average risk of suicide is 250 per 100,000 admissions in psychiatric hospitals and 1.8 per 100,000 admissions in general hospitals, which is four to five times more than the general population. ${ }^{8}$ The wide range of suicide rates is possibly due to the difference in the settings where the studies are conducted. ${ }^{9}$ Many of the suiciderelated studies in India are conducted in medical and general hospital settings, where the characteristics of risk factors significantly differ from psychiatric inpatient settings.

Indian data on suicide in psychiatric inpatient settings have been recently studied at NIMHANS. A retrospective study by Shinde et al. included $1,03,252$ psychiatric inpatient admissions over a period of 26 years of which 333 patients died during the hospital stay. Leading causes of death among psychiatric inpatients were found to be cardiovascular system disorders (43.6\%), followed by respiratory system disorders (14.9\%), nervous system disorders $(9.9 \%)$, and infections $(10.1 \%)$. In $7 \%$ of psychiatric inpatients who died, the cause of death was reported to be suicide. ${ }^{10}$

The characteristics and risk factors of suicides in inpatient settings and general population differ. Moreover, the identified risk factors for IPS have a relatively low degree of association between the risk factor and suicide. ${ }^{5}$ Nevertheless, studies worldwide show that psychiatric patients, especially inpatients, are at a higher risk ofsuicide. ${ }^{6,11,12,13}$ The risk factors shall be discussed in detail in the article, later.

Modes of suicide attempts: In developed countries, the commonmodes of suicide attempts in general population are firearm injuries, car exhaust asphyxiation, and poisoning. ${ }^{1}$ While in developing countries, the usual modes are poisoning, hanging, self-immolation and drowning. Poisoning using pesticides is the most common mode of suicide attempt in psychiatric patients with agricultural background. ${ }^{1,14}$ The picture is almost the same in most south Indian studies - i.e., poisoning and hanging, followed by self-immolation. ${ }^{15}$

The mode of IPS differs from modes in general population. The mode of IPS differs based on the difference in hospital settings. Mostly, the accessibility and availability of lethal means determine the mode of suicide among psychiatric inpatients. Hanging, jumping from a height, poisoning, and self-injuries are the common modes of IPS. Hence, prevention strategies should target accessibility and availability of the above. ${ }^{7}$ The infrastructure of psychiatric wards should be designed in such a way that it limits access to the above lethal means.

\section{PREVENTION OF IPS: AN APPROACH}

Foreseeing a suicide attempt is the cornerstone of suicide prevention strategies. However, prediction of time and mode of suicide is the most difficult task, and hence the accurate prediction of risk is difficult. ${ }^{12}$ The task of foreseeing suicide can be made more predictable if a thorough and timely assessment of risk factors and protective factors is done. Any person in a severely stressful situation can harbor a suicidal idea. However, the resilience and coping strategies of the individual will help him/her to bounce back to normal life. Therefore, defense mechanisms and coping strategy commonly used by the individual also needs to be assessed. Unfortunately, risk factors are not adequately assessed in about $60 \%$ of suicides of psychiatric patients. ${ }^{16}$

The risk factors for suicide in general population are widely studied, and in most studies, the factorsare broadly divided into psychosocial and psychiatric. The psychosocial factors are marital disruption, abusive relationships, living alone, unemployment, lower socioeconomic status, poor physical health and family history of suicide. ${ }^{1,17}$ The marital status 
of a person is a factor with a good degree of association in the western world — i.e., marriage is a protective factor in the western population. However, in India, marriage is not found to be strong a protective factor for suicide, as most people in the country are getting married as a part of the cultural setting. ${ }^{15}$ The important psychiatric factors are major depressive disorder, substance use disorders, emotionally unstable personality disorder, and history of suicide attempt. ${ }^{1,17}$

After the thorough risk assessment, the patient should be stratified into low and high-risk groups based on the risk factors obtained. Further interventions for suicide prevention need to be tailored accordingly for each individual.

Mrazek \& Haggarty $^{18}$ proposed a model of the spectrum of interventions for mental health protection. The spectrum begins with prevention at three levels: "Universal" for the general population, "Selective" for 'at risk population' and "Indicated" for those who have attempted suicide before. The above model may be used to classify the individual and intervene for suicide prevention in general population. Even though the risk factors for IPS differ, the general principles for suicide prevention can be utilized for managing the inpatients.

A stepwise approach is to be followed for the prevention of IPS in general hospital and psychiatric inpatient settings. Jacob et al. (2007) introduced BSAFE (Basic Suicide Assessment Five-step Evaluation $)^{19}$ and later, Centre for Addiction and Mental Health, Canada (2010) brought SAFE-T (Suicidal Assessment Five Step Evaluation \& Triage) strategies with modifications for interventions. This is a stepwise approach, with five steps, for patients who are 'at risk' for suicides, and the approachis discussed below.

\section{STEP 1: IDENTIFICATION OF THE RISK FACTORS}

Numerous risk factors for IPS have been identified and discussing all risk factors is beyond the scope of this article. Hence a few important risk factors are being discussed below (Box 1).

\section{a. Epidemiological Factors}

American Foundation for Suicide Prevention studied suicides among general population and found that suicides are 3.5 times higher in males. But female attempters tend to show higher rates of reported nonfatal suicidal behavior and suicide ideation, and males have much higher rates of completed suicides. ${ }^{15,20}$ While in India, the Nation Crime Records Bureau (NCRB) shows that suicide in males outnumber females (Male: Female $=2: 1$ ). But recent studies in India reveal a narrowing of margin between males and females (Male: Female = 1.3:1). ${ }^{1}$ Unlike the general population suicides, the gender difference is minimal in IPS. Females outnumber males marginally. 5,11,21

When compared to suicides in the general population, age has a lesser degree of association as a predictor of IPS. An Indian study showed that the suicide rate in general population is the highest in the 15-29 years age group (38 per100,000 population) followed by the 30-44 years group ( 34 per 100,000 population). ${ }^{22}$ Hospital suicide rates were considerably higher than the corresponding general population rates for all age groups and were particularly high in age categories of 25-29, 30-34, 40-44, and 55-59 years after controlling for sex and calendar year. ${ }^{23}$ However, there are contradicting studies stating age between 20-40 years, living alone with unemployment, and poor socioeconomic support as risk factors with less degree of association among IPS, though they are significant factors in general population suicides. ${ }^{24-26}$

\section{b. Mental Disorders}

The psychiatric risk factors have more degree of association than the psychosocial risk factors for suicides in inpatient setting. Psychiatric patients are at a higher risk for suicide attempt than the general population. This risk of suicide is further increased in psychiatric inpatient setting. ${ }^{7,25,26,27}$ Majority of the inpatients (98\%) who attempt suicide in general hospital setting have an Axis I diagnosis at the time of suicide attempt. Patients suffering from depression and schizophrenia represent the highest risk group. ${ }^{28,29}$ 
- Homeless

- Chronic mental illness, affective and psychotic disorders, longer duration of disorder

- Male gender

- Previous self-harm

- Previous suicide attempt

- Planned suicide attempt

- Suicidal behavior before admission

- Suicide attempt \& ideation during admission

- Recent bereavement

- Increased length of stay

- History of suicide in a first-degree relative

- Family history of psychiatric illness

- Major depressive disorder

- Multiple previous admissions

- AOWL during admit

- Extrapyramidal symptoms, akathisia

- Greater number of ward transfers

- Part time employment

- Single

- Lives alone

In schizophrenia patients with active psychotic symptoms, the risk of IPS is higher when compared to nonpsychoticperiod. ${ }^{24,30,31}$ Initial studies showed an increased risk of IPS in patients with Schneider's First Rank Symptoms (FRS). However, later, many studies showed that the association between the IPS and FRS is weak. Persistent command auditory hallucinations increase the risk of IPS, especially if associated with persecutory delusions and derogatory content. ${ }^{32}$ Negative schizophrenia of longer duration (i.e., more than 185 days of inpatient stay) is a risk factor for IPS in late stages of the illness. ${ }^{25,29,33}$ Hopelessness and depressed mood in schizophrenic inpatients are found to be strongly associated with suicide. ${ }^{25}$
Major Depressive disorder (MDD) is a very important risk factor for IPS, especially when untreated. ${ }^{28,34}$ The risk of IPS in depressive patients is further increased if hopelessness, worthlessness and anxiousness are elicited in the episode..$^{35}$ The risk of IPS goes further high if associated with history of previous deliberate self-harm attempt ${ }^{11,36}$ and expressing suicidal intent. ${ }^{37}$ BPAD NOS (Bipolar Disorder Not Otherwise Specified) and chronic pain syndromes are other risk factors with cumulative effect for depressive disorder. ${ }^{38-40}$ In severe depression, the activation phenomenon following the initiation of antidepressants increases the risk of suicide. ${ }^{41}$ This is due to differential improvement of psychomotor activity and suicidal thoughts. ${ }^{42}$ The psychomotor activity responds to medications and improves faster than the suicidal ideations. Hence, the inability to execute the suicidal ideas due to psychomotor retardation is lost, thereby resulting in suicide attempt.

Substance use disorders, when comorbid to any psychiatric illness, increase the risk of IPS by twofold. ${ }^{43,44,45}$ Similar studies have been conducted proving the same for cannabis, opioids and cocaine..$^{25,43}$ In a study of 527 abstinent opiatedependent clients, Roy et al. found that almost $40 \%$ had a history of suicide attempts and that family history of suicidal behavior, alcohol dependence, cocaine dependence and treatment with antidepressant medication were significant predictors of these attempts. Cottler et al. found that alcohol use disorder and depression were significant predictors of suicidal ideation for both males and females. They highlighted "the need to discuss suicidal thoughts among depressed drug users for early treatment and prevention". In the Copenhagen City Heart Study in Denmark, Flensborg-Madsen et al. concluded that alcohol use disorders were associated with a "highly increased risk of completed suicide" among 18,146 subjects. ${ }^{43}$

The psychosocial and psychiatric factors that contribute to the IPS are colored by the prismatic spectrum of personality traits and disorders. Hence, the risk assessment of IPS must be donein the background of personality traits and disorders. Many studies have been conducted on the 
background of personality disorders. Patients with borderline personality disorders and narcissistic personality disorders have been found to be at a higher risk for IPS.

Borderline personality disorder individuals who die by suicide differ from those with the disorder typically encountered in acute psychiatric settings. The lethality of suicide attempts by those with borderline personality disorder results from an interaction between impulsivity and the violentaggressive features associated with cluster B comorbidity. Further, the anxious trait of harm avoidance appears to be protective against suicidal behavior resulting in death. ${ }^{82,83}$ Hence, mental illness, including personality traits, should be diagnosed at the earliest and managed appropriately.

Physical illness increases the risk for suicide. Patients with physical illness, especially chronic illness, have two to three times higher risk of completed suicide than those without. ${ }^{17}$ Also, many suicide victims with physical illness (52-88\%) have suffered from concurrent mental disorders. ${ }^{34,48}$ Chronic neurological illnesses that affect the locomotor ability are a risk factor for IPS. ${ }^{46,47}$

Jacob et al., ${ }^{49}$ in their comparative study on subjects with a seizure disorder and bronchial asthma, found that $34 \%$ of the epilepsy group and $13.3 \%$ of the asthma group had a diagnosis of major depressive disorder. Sixteen percent of the epilepsy group had a history of at least one suicide attempt in the previous year, and $20 \%$ of the group expressed current suicidal ideation.

A study by Latha and Bhat ${ }^{5}$ on the prevalence of suicidal ideation in terminally ill cancer patients reported that $9.2 \%$ had severe suicidal ideations. $3.8 \%$ of the patients with suicidal ideation had a history of major depressive disorder. Factors such as the presence of pain and awareness of diagnosis and prognosis of cancer contributed to the depressive states. The study also concluded that suicidal ideation and desire for death appeared to be linked exclusively to the presence of a psychiatric disorder.
An increased likelihood of suicidal ideation, attempts and completions have been reported in patients who have central nervous systemdysfunction, ${ }^{51,52}$ general medical disorders, ${ }^{53-}$ 56 and specific symptoms such aspain ${ }^{57,58}$ and physical limitations. ${ }^{59}$ In addition, other factors associated with suicide are also found in patients hospitalized for medical illness, such as substance abuse,${ }^{60}$ advanced age ${ }^{61,62}$ unemployment and other financial stressors, feelings of hopelessness, and socialisolation. ${ }^{63}$

Absconding and going absent without leave are common within psychiatric wards, with rates between $34 \%$ and $39 \% .{ }^{64,65}$ Some of the adverse consequences of absconding include loss of treatment, violence to others, self-neglect, selfharm, and suicide. ${ }^{65-67}$ Controlled studies have found absconding to be a significant risk factor for suicide amongst psychiatric inpatients. $5,31,68$ In the UK, Powell and colleagues ${ }^{11}$ reported that $63 \%$ of inpatients who died by suicide outside of the hospital site were absent without authorized leave at the time of death. Other studies have reported lower (36\% to $40 \%$ ), but still substantial, rates of absconding when the suicide occurred..$^{5,30,69}$ Absence without leave increases the risk of IPS. ${ }^{30,39,70,71}$

\section{STEP 2: IDENTIFICATION OF PROTECTIVE FACTORS}

In the mid 90's, the suicide rates in the US were increasing alarmingly among the general population and in inpatient settings. This forced the government to encourage studies on factors related to suicide to cease the exponential progress of suicides rates. The Risk Management Foundation of the Harvard Medical Institutions (RMFHMI) in 1996 extensively studied various suicide factors and brought forward a few protective factors for suicide. A similar study was conducted by Centre for Applied Research in Mental Health and Addiction in 2007 (CARMHA, 2007) and found certain protective factors that were significantly correlated with IPS. The study by CARMHA supported the protective factors identified by RMFHMI. Among the various factors, responsibility to others, 
especially towards children, is found to be the major factor that prevents a person from attempting suicide. The other factors included life satisfaction, self-efficacy, hope for future, reality testing ability and positive coping skills. Certain deterrent religious beliefs consider suicide as immoral, thereby preventing suicides. The Indian statistics show that the suicides rates are comparatively less in Muslim community. ${ }^{86}$ Positive psychosocial and family support along with positive therapeutic relationship can prevent IPS to some extent. Fear of the act of suicide and fear of social disapproval are certain social factors that protect a person from committing suicide. ${ }^{39}$

No-harm or No-suicide contracts: No-harm contracts are based on a statement from the person that they will not harm themselves or will contact the clinician or another specified person if they feel unable to maintain their safety. There is no empirical evidence on the effectiveness of such contracts. ${ }^{72}$ Therefore, clinicians are to avoid the use of 'no suicide' or 'no harm' contracts as they are ineffective in the management of suicidal clients, are not supported by evidence, and are no substitute for a thorough clinicalevaluation. ${ }^{73}$

\section{STEP 3: CONDUCT OF SUICIDAL ENQUIRY (DO NOT HESITATE TO ENQUIRE IDEATIONS)}

Whenever a suicidal intent or ideation is explored from an inpatient, the suicidal intent should be assessed under the following headings and needs to be documented: Severity of intent, lethality, degree of ambivalence (Die or not to), intensity and frequency of suicidal thoughts, availability of methods, rehearsals, and suicide note. The same need to be assessed and documented if a history of a previous attempt is present. Expressing suicidal intent and history of previous suicidal attempt are the most predictive factors. ${ }^{11,25}$ Forty percent of the IPS attempters have never expressed suicidal ideas, and $78 \%$ have denied ideas in the previous week of the attempt. This shows that the patient may not even expressa suicidal idea before an attempt at suicide and if a patient expresses suicidal ideas, then it needs to be closely observed and intervened adequately.

\section{STEPS 4 AND 5}

The level of risk of IPS is assessed based on the above three steps and patients are categorized into high risk and lowrisk groups. Stratification into high and low-risk groups is mainly based on the clinical experience of the physician and the number of risk factors identified. Documentation at each step is inevitable, as this may be the only legal evidence to evade lawsuits and other legal allegations. Once the stratification is done, the patient needs to be adequately monitored and intervened. An attempt may be done to reduce the IPS risk by managing the modifiable risk factors. As mentioned above, early diagnosis and adequate pharmacological and nonpharmacological interventions for mental disorders are the first and foremost strategies for IPS prevention.

The next major factor is the hospital-environmental factors, which is a modifiable risk factor. Most suicides occur in the premises of the ward rather than in areas where direct staff monitoring is possible. The most vulnerable period is when the patient is removed from the continuous observation unit..$^{30,39,70,71}$ Hence, accessibility and availability of lethal means need to be restricted in and around the hospital premises and follow-up monitoring of the patients is mandatory, especially for those recently removed from continuous observation unit. The putative ideal design for an inpatient unit is one encompassing the greatest chance of keeping patients under direct vision at all times, together with the absence of physical hazards. Infrastructural constructions and modifications of a psychiatric hospital should be so designed that the access to means are minimized maximally and observation of the patient is maximum possible. Adequate staff pattern (both physician and nursing staff) is mandatory, thereby maintaining adequate staff to patient ratio. Low staff to patient ratio will aggravate the risk of IPS during this period..$^{74,75,76,77}$

The mode of IPSis usually determined by the accessibility and availability of lethal means. Also, each hospital setting will have a particular 
infrastructural flaw (unit design vulnerability) that provides access to a particular mode of suicide which should be taken care of. The usual mode of IPS may be understood if a detailed probe is done into the history of that particular unit design and its vulnerability. Hence, precautionary measures should be targeted to prevent the common mode related to that particular hospital setting. Hanging, jumping from a height, poisoning and self-injuries are the common modes of IPS in India. Hence, prevention strategies should target accessibility and availability for the above, which includes infrastructural modifications of hospital settings.

Patients who are at a risk of suicide should be kept in a continuous observation unit. While constructing a continuous observation psychiatric unit, care should be taken to facilitate maximum observation of patients with minimal effort and minimum staff. The nursing station is to be built in the critical area from where observation of all the patients is maximally possible. Infrastructural modifications include toughened safety glasses on all windows, replacement of ceiling fans, restricting the access to staircases/roof, avoiding door and doorknobs wherever possible, and adequate maintenance to avoid exposed pipelines and telephones cables. ${ }^{78-80}$

In bathrooms and bedrooms, acoustic ceiling tiles could be removed by patients and exposed plumbing, piping or ductwork could be used as anchors for hanging. The Lieberman et al. study lists numerous points about the physical environment that may require attention, including training cleaning staff to ensure their cleaning fluids are kept secure, and their carts always attended, and informing visitors not to bring in potentially lethal items such as plastic bags. Mills et al. systematically undertook root cause analysis of 185 IPS and suicide attempts in Veteran Affairs (VA) hospitals. Doors and wardrobe cabinets accounted for $41 \%$ of the anchor points for hanging. The careful analysis led them to recommend eliminating doors when not required; removing doors on wardrobe cabinets and replacing the rods and hangers with shelves; eliminating belts, shoelaces, and safety razors; and ensuring there is a protocol in place to eliminate access to drugs that could be used in overdose.

The bathrooms should have maximum access from outside with adequate privacy. Hooks and curtain rods may be replaced by shelves to prevent hanging. Careless use of cleaning lotions is to be avoidedtoprevent deliberate self-harm by poisoning. Hence, education and training of the nursing staff of basic grade areimportant. Removal and safe disposal of the sharps from the less observed areas of the psychiatry units should not be ignored.

Mills et al. recommended conducting regular environmental rounds to spot potential hazards. Finally, they were able to develop and implement the MHEOCC (Mental Health Environment of Care Checklist) to review the environment of care in psychiatric hospitals and identify suicide hazards requiring abatement. The most common type of hazard was ligature anchor points, that is, protrusions capable of supporting the weight of a person more than $100 \mathrm{lbs}$. In the United Kingdom, hanging was the method in $77 \%$ of IPSbetween 1999 and 2007. The most common ligature points were doors, hooks or handles, windows, belts, and sheets or towels. The use of shoelaces, doors, and windows increased over time. ${ }^{81}$ Hence, a special committee may be constituted with periodic daily rounds to identify and remove potentially hazardous objects, thereby limiting the access to weapons. ${ }^{34}$

To summarize, suicide prevention strategies need to be tailored in psychiatric and non-psychiatric patients according to differing patient risk characteristics. Early diagnosis and adequate treatment of psychiatric disorders along with appropriate infrastructural modifications can prevent IPSto a great extent.

\section{REFERENCES}

1. Radhakrishnan R, Andrade C. Suicide: An Indian perspective; Indian J Psychiatry 2012; 54:304-19.

2. Oehmichen M, Staak M. Suicide in the psychiatric hospital; International trends and medico-legal aspects. Acta Med Leg Soc (Liege) 1988; 38:215-23. 
3. Cotton PG, Drake Jr RE, Whitaker A, Potter J. Dealing with suicide on a psychiatric inpatient unit. Hosp Community Psychiatry 1983; 34:55-9.

4. Simon RI, Shuman DW. Clinical manual of psychiatry and the law. Washington, DC: American Psychiatric Publishing; 2007.

5. King EA, Baldwin DA, Sinclair JM, Campbell MJ. The Wessex Recent In-Patient Suicide Study, 2. Case control study of 59 in-patient suicides. $\mathrm{Br}$ J Psychiatry 2001; 178:537-542.

6. Harris EC, Barraclough B. Suicide as an outcome for mental disorders: A meta-analysis. Br J Psychiatry 1997; 170:205-228.

7. Busch KA, Fawcett J, Jacobs DG. Clinical correlates of inpatient suicide. J Clin Psychiatry 2003; 64:14-9.

8. Martelli C, Awad H, Hardy P. In-patients suicide: epidemiology and prevention. Encephale 2010; 36 Suppl 2:D83-91.

9. Deisenhammer EA, DeCol C, Honeder M, Hinterhuber $\mathrm{H}$, Fleischhacker WW. Inpatient suicide in psychiatric hospitals. Acta Psychiatr Scand 2000; 102:290-4.

10. Shinde SS, Nagarajaiah J, Narayanaswamy JC, Viswanath B, Kumar NC, Gangadhar BN, et al. Indian J Psychol Med 2014; 36:142-6.

11. Powell J, Geddes J, Deeks J, Goldacre M, Hawton K. Suicide in psychiatric hospital inpatients. Risk factors and their predictive power. Br J Psychiatry 2000; 176:266-72.

12. Appleby L. Suicide in psychiatric patients: risk and prevention. Br J Psychiatry 1992; 161:749-58.

13. Madsen T, Agerbo E, Mortensen PB, Nordentoft M. Predictors of psychiatric inpatient suicide: a national prospective register-based study. J Clin Psychiatry 2012; 73:144-51.

14. Accidental Deaths and Suicides in India 2008. New Delhi; Ministry of Home Affairs Government of India.

15. Vijayakumar L. Indian Research on Suicide. Indian J Psychiatry 2010; 52 Suppl:S292-6.

16. Burgess P, Pirkis J, Morton J, Croke E. Lessons from a comprehensive clinical audit of users of psychiatric services who committed suicide. Psychiatr Serv 2000; 51:1555-60.

17. Cheng AT, Chen TH, Chen CC, Jenkins R. Psychosocial and psychiatric risk factors for suicide. Case-control psychological autopsy study. Br J Psychiatry 2000; 177:360-5.

18. Mrazek PJ, Haggerty RJ. Reducing risks for mental disorders: Frontiers for preventive intervention research. Washington DC: National Academy Press; 1994. pp. 22-26

19. Jacobs DG, Brewer ML, Klein-Benheim M. Suicide assessment: an overview and recommended protocol. In: Jacobs DG, ed. The Harvard Medical School guide to suicide assessment and intervention. San Francisco (CA): Jossey-Bass Publishers; 1999. pp. 3-39.
20. Canetto SS, Sakinofsky I. The gender paradox in suicide. Suicide Life Threat Behav 1998; 28(1); 1-23.

21. Proulx F, Lesage AD, Grunberg F. One hundred inpatient suicides. Br J Psychiatry1997; 171:247-50.

22. Gururaj G, Isaac MK. Epidemiology of suicides in Bangalore. Publication 44. Bengaluru: National Institute of Mental Health and Neuro Sciences; 2001.

23. Tseng MC, Cheng IC, Hu FC. Standardized mortality ratio of inpatient suicide in a general hospital. J Formos Med Assoc 2011; 110:267-9.

24. Brecić P, Ostojić D, Vidović D, Jukić V, Bagarić D, Vilibić M, et al. Characteristics of patients who committed suicide during hospitalization in Psychiatric Hospital "Vrapce" in the period 1996-2006. Coll Antropol 2009; 33:233-6.

25. Roy A, Draper R. Suicide among psychiatric hospital inpatients. Psychol Med 1995; 25:199-202.

26. Chavan BS, Singh GP, Kaur J. Psychological autopsy of 101 suicide cases from northwest region of India. Indian J Psychiatry 2008; 50:34-8.

27. Gajalakshmi V, Peto R. Suicide Rates in Tamil Nadu, South India: Verbal autopsy of 39,000 deaths in 1997-98. Int J Epidemiol 2007; 36:203-7.

28. Lieb M, Palm U, Meyer S. Risk Factors for inpatient suicide. Psychiat Prax 2014; 41:195-9

29. Sharma V, Persad E, Kueneman K. A closer look at inpatient suicide; J Affect Disord 1998; 47:123-9

30. Shah A, Ganesvaran T. Suicide among psychiatric inpatients with schizophrenia in an Australian mental hospital. Med Sci Law 1999; 39:251-9.

31. Dong JY, Ho TP, Kan CK. A case-control study of 92 cases of inpatient suicides. J Affect Disord 2005; 87:91-9.

32. Harkavy-Friedman JM, Kimhy D, Nelson EA, Venarde DF, Malaspina D, Mann JJ. Suicide attempts in schizophrenia: The role of command auditory hallucinations for suicide. J Clin Psychiatry 2003; 64:871-4.

33. Deisenhammer EA, Huber M, Kemmler G, Weiss EM, Hinterhuber H. Psychiatric hospitalizations during the last 12 months before suicide. Gen Hosp Psychiatry 2007; 29:63-5.

34. Brent DA, Perper JA, Goldstein CE, Kolko DJ, Allan MJ, Allman CJ, et al. Risk factors for adolescent suicide: a comparison of adolescent suicide victims with suicidal inpatients. Arch Gen Psychiatry 1988; 45:581-8.

35. Bolton JM, Cox BJ, Afifi TO, Enns MW, Bienvenu OJ, Sareen J. Anxiety disorders and risk for suicide attempts: findings from the Baltimore Epidemiologic Catchment area follow-up study. Depress Anxiety 2007; 25:477-81.

36. Erlangen A, Zarit SH, Tu X, Conwell Y. Suicide among older psychiatric inpatients: an evidence-based study of a high-risk group. Am J Geriatr Psychiatry 2006; 14:73441 . 
37. Joyce B, Wallbridge H. Effects of suicidal behavior on a psychiatric unit nursing team. J Psychosoc Nurs Ment Health Serv 2003; 41:14-23.

38. Bethell J, Rhodes AE. Depressed mood in the suicidal population. Can J Psychiatry 2007, 52:744-8.

39. Sakinofsky I, Webster G. The epidemiology of suicide in Canada. In Cairney J, Streiner DL (Eds.), Mental Disorder in Canada: An Epidemiological Perspective. Toronto: University of Toronto Press; 2010. p. 379

40. Cassells C, Paterson B, Dowding D, Morrison R. Longand short-term risk factors in the prediction of inpatient suicide: review of the literature. Crisis 2005; 26:53-63.

41. Thase ME. Do antidepressants really work? A clinician's guide to evaluating the evidence. Current Psychiatry Rep 2008; 10:487-94.

42. Flensborg-Madsen T. Knop J. Mortensen EL, Becker U, Sher L, Grønbaek M. Alcohol use disorders increase the risk of completed suicide-irrespective of other psychiatric disorders: A longitudinal cohort study. Psychiatry Res 2009; 167:123-30.

43. Rehm J, Baliunas D, Brochu S, Fischer B, Gnam W, Patra J, et al. The costs of substance abuse in Canada 2002 [monograph on the Internet]. Ottawa: Canadian Centre on Substance Abuse. 2006 [cited 2015 Sep 6] Available from: http:/ / www.ccdus.ca/Resource\%20Library/ccsa011332-2006.pdf.

44. Iligen MA, Zivin K, Austin KL, Bohnert AS, Czyz EK, Valenstein $M$, et. al. Severe pain predicts greater likelihood of subsequent suicide. Suicide Life Threat Behav 2010; 40:597-608.

45. Bair MJ, Robinson RL, Katon W, Kroenke K. Depression and pain comorbidity: a literature review. Arch Intern Med 2003; 163:2433-45.

46. Lin EH, Heckbert SR, Rutter CM, Katon WJ, Ciechanowski P, Ludman EJ; Depression and increased mortality in diabetes: Unexpected causes of death. Ann Fam Med S 2009; 7:414-21.

47. Suominen K, Isometsa E, Heila H, Lonnqvist J, Henriksson M. General hospital suicides-a psychological autopsy study in Finland. Gen Hosp Psychiatry 2002; 24:412-6.

48. Jacob R, Kumar MS, Rajkumar R, Palaniappun V. A study to assess depression, its correlates and suicidal behavior in epilepsy. Indian J Psychiatry 2002; 44:161-4.

49. Latha KS, Bhat SM. Suicidal behavior among terminally ill cancer patients. Indian J Psychiatry 2005; 45:79-83.

50. Jones JE, Herman BP, Barry JJ, Gilliam FG, Kanner AM, Meador KJ. Rates and risk factors for suicide, suicidal ideation and suicide attempts in chronic epilepsy. Epilepsy Behav 2003. 4 Suppl 3:S31-8.

51. Schoenfeld M, Myers RH, Cupples LA, Berkman B, Sax DS, Clark E. Increased rate of suicide among patients with Huntington's disease. J Neurol Neurosurg Psychiatry 1984; 47:1283-7.
52. Hughes D, Kleespies P. Suicide in the medically ill. Suicide Life Threat Behav 2001; 31 Suppl:48-59.

53. Komiti A, Judd F, Grech P, Mijch A, Hoy J, Lloyd JH, et al. Suicidal behaviour in people with HIV/AIDS: A review. Aust N Z J Psychiatry 2001; 35:747-57.

54. Björkenstam C, Edberg A, Ayoubi S, Rosen M. Are cancer patients at higher suicide risk than the general population? Scand J Public Health 2005; 33:208-14.

55. Abram HS, Moore GL, Westervelt FB Jr. Suicidal behavior in chronic dialysis patients. Am J Psychiatry 1971; 127:1199-204.

56. Fishbain DA. The association of chronic pain and suicide. Semin Clin Neuropsychiatry 1999; 4:221-7.

57. Tang NK, Crane C. Suicidality in chronic pain: A review of the prevalence, risk factors and psychological links. Psychol Med 2006; 18:1-12

58. Kaplan MS, McFarland BH, Huguet N, Newsom JT. Physical illness, functional limitations, and suicide risk: A population-based study. Am J Orthopsychiatry 2007; 77:56-60.

59. Bostwick JM, Seaman JS. Hospitalized patients and alcohol: Who is being missed? Gen Hosp Psychiatry 2004; 26:59-62.

60. Waern M, Rubenowitz E, Runeson B, Skoog I, Wilhelmson K, Allebeck P. Burden of illness and suicide in elderly people: Case control study. BMJ 2002; 324:1355.

61. Juurlink DN, Herrmann N, Szalai JP, Kopp A, Redelmeier DA. Medical illness and the risk of suicide. Arch Intern Med 2004; 164:1179-84.

62. Institute of Medicine. Risk Factors for Suicide: Summary of a Workshop; Washington, DC: National Academy Press; 2001.

63. Neilson T, Peet M, Ledsham R, Poole J. Does the nursing care plan help in the management of psychiatric risk? J Adv Nurs 1996, 24:1201-6.

64. Bowers L, Jarrett M, Clark N, Kiyimba F, McFarlane L. Absconding: why patients leave. J Psychiatr Ment Health Nurs 1999; 6:199-205.

65. Bowers L, Jarrett M, Clark N. Absconding: a literature review. J Psychiatr Ment Health Nurs 1998; 5:343-53.

66. Dickens GL, Campbell J. Absconding of patients from an independent UK psychiatric hospital: A 3-year retrospective analysis of events and characteristics of absconders. J Psychiatr Ment Health Nurs 2001; 8:54350 .

67. Muir-Cochrane E, Mosel KA. Absconding: a review of the literature 1996-2008. Int J Ment Health Nurs 2008; 17:370-8.

68. Hunt IM, Kapur N, Webb R, Robinson J, Burns J, Turnbull P, et al. Suicide in current psychiatric inpatients: a case-control study. Psychol Med 2007; 37:8317.

69. Hunt IM, Windfuhr K, Shaw J, Appleby L, Kapur N. Ligature points and ligature types used by psychiatric 
inpatients who die by hanging. A national study. Crisis 2012; 33:87-94.

70. Hunt IM, Windfuhr K, Swinson N, Shaw J, Appleby L, Kapur N, et al. Suicide amongst psychiatric in-patients who abscond from the ward: a national clinical survey. BMC Psychiatry 2010; 10:14.

71. de Leo D, Sveticic J. Suicides in psychiatric in-patients: what are we doing wrong? Epidemiol Psichiatr Soc 2010; 19:8-15.

72. Kleespies PM, Dettmer EL. An evidence-based approach to evaluating and managing suicidal emergencies. J Clin Psychol 2000; 56:1109-30.

73. Stewart D, Bowers L, Warburton F. Constant special observation and self-harm on acute psychiatric wards: a longitudinal analysis. Gen Hosp Psychiatry 2009; 31:523-30.

74. Bowers L, Dack C, Gul N, Thomas B, James K. Learning from prevented suicide in psychiatric inpatient care: An analysis of data from the National Patient Safety Agency. Int J Nurs Stud 2011; 48:1459-65.

75. Coleman JC, Paul GT. Relationship between staffing ratios and effectiveness of inpatient psychiatric units. Psychiatr Serv 2001; 52:1374-9.

76. Bassett D, Tsourtos G. Inpatient suicide in a general hospital psychiatric unit. A consequence of inadequate resources? Gen Hosp Psychiatry 1993; 15:301-6.

77. Benensohn HS, Resnik HL. Guidelines for "suicideproofing” a psychiatric unit. Am J Psychother 1973; 27:204-12.

78. Cardell R, Bratcher KS, Quinnett P. Revisiting “suicide proofing" an inpatient unit through environmental safeguards: a review. Perspect Psychiatr Care 2009; 45:36-44.

79. Lieberman DZ, Resnik HL, Holder-Perkins V. Environmental risk factors in hospital suicide. Suicide Life Threat Behav 2004; 34:448-53.
80. Sakinofsky I. Preventing suicide among inpatients. Can J Psychiatry 2014; 59:131-140.

81. McGirr A, Paris J, Lesage A, Renaud J, Turecki G. Risk factors for suicide completion in borderline personality disorder: a case-control study of cluster B comorbidity and impulsive aggression. J Clin Psychiatry 2007; 68:721-9.

82. Kullgren G. Factors associated with completed suicide in borderline personality disorder. J Nerv Ment Dis 1988; 176:40-4.

83. Combs H, Romm S. Psychiatric inpatient suicide: A literature review. Primary Psychiatry 2007; 14:67-74.

84. Kisely S. Smith M. Lawrence D, Maaten S. Mortality in individuals who have had psychiatric treatment: population-based study in Nova Scotia. Br J Psychiatry 2005; 187:552-8.

85. Shah A, Chandia M. The relationship between suicide and Islam: a cross-national study. J Inj and Violence Res; 2:93-9.

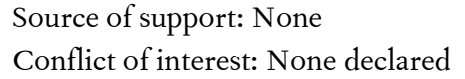

First submitted: $24^{\text {th }}$ October 2015

Published online: $7^{\text {th }}$ January 2018 